\title{
Oxo Crater on (1) Ceres: Geological History and the Role of Water-ice
}

\author{
A. Nathues ${ }^{1}$, T. Platz ${ }^{1}$, M. Hoffmann ${ }^{1}$, G. Thangjam ${ }^{1}$, E. A. Cloutis ${ }^{2}$, D. M. Applin ${ }^{2}$, L. Le Corre ${ }^{1,3}$, V. Reddy ${ }^{1,4}$, K. Mengel $^{5}$, \\ S. Protopapa ${ }^{6}$, D. Takir ${ }^{7}$, F. Preusker ${ }^{8}$, B. E. Schmidt ${ }^{9}$, and C. T. Russell ${ }^{10}$ \\ ${ }^{1}$ Max Planck Institute for Solar System Research, Justus-von-Liebig-Weg 3, D-37077 Goettingen, Germany; nathues@mps.mpg.de \\ ${ }^{2}$ University of Winnipeg, Winnipeg, MB R3B 2E9, Canada \\ ${ }^{3}$ Planetary Science Institute, 1700 East Fort Lowell Rd, Suite 106, Tucson, AZ 85719-2395, USA \\ ${ }^{4}$ Lunar and Planetary Laboratory, University of Arizona, Tucson, AZ, USA \\ ${ }^{5}$ IELF, TU Clausthal, Adolph-Roemer-Straße 2A, D-38678 Clausthal-Zellerfeld, Germany \\ ${ }^{6}$ University of Maryland, Department of Astronomy, College Park, MD 20742, USA \\ 7 SETI Institute, Mountain View, CA 94043, USA \\ ${ }^{8}$ German Aerospace Center (DLR), Institute of Planetary Research, D-12489 Berlin, Germany \\ ${ }^{9}$ Georgia Institute of Technology, Atlanta, GA, USA \\ ${ }^{10}$ Institute of Geophysics and Planetary Physics, Dept. of Earth, Planetary and Space Sciences, \\ University of California Los Angeles, Los Angeles, CA, USA \\ Received 2017 March 1; revised 2017 June 14; accepted 2017 June 14; published 2017 August 4
}

\begin{abstract}
Dwarf planet Ceres $(\varnothing \sim 940 \mathrm{~km})$ is the largest object in the main asteroid belt. Investigations suggest that Ceres is a thermally evolved, volatile-rich body with potential geological activity, a body that was never completely molten, but one that possibly partially differentiated into a rocky core and an ice-rich mantle, and may contain remnant internal liquid water. Thermal alteration and the infall of exogenic material contribute to producing a (dark) carbonaceous chondritic-like surface containing ammoniated phyllosilicates. Here we report imaging and spectroscopic analyses of data on the bright Oxo crater derived from the Framing Camera and the Visible and Infrared Spectrometer on board the Dawn spacecraft. We confirm that the transitional complex crater Oxo $(\varnothing \sim 9 \mathrm{~km})$ exhibits exposed surface water-ice. We show that this water-ice-rich material is associated exclusively with two lobate deposits at pole-facing scarps, deposits that also contain carbonates and admixed phyllosilicates. Due to Oxo's location at $-4802 \mathrm{~m}$ below the cerean reference ellipsoid and its very young age of only $190 \mathrm{ka}(1 \sigma:+100 \mathrm{ka},-70 \mathrm{ka})$, Oxo is predestined for ongoing water-ice sublimation.
\end{abstract}

Key words: minor planets, asteroids: general

\section{Introduction}

The Dawn spacecraft (Russell \& Raymond 2011) is equipped with two Framing Cameras (FC) (Sierks et al. 2011). Camera FC2 has obtained, to date, more than 55,000 images of Ceres in seven colors $(0.44-0.98 \mu \mathrm{m})$ and one clear filter, performing global color mapping of the cerean surface at a resolution of $\sim 140 \mathrm{~m} \mathrm{pixel}^{-1}$ (Nathues et al. 2016; Russell et al. 2016). However, higher resolution seven-filter $\left(\sim 35 \mathrm{~m} \mathrm{pixel}^{-1}\right)$ color data have been obtained for selected sites. One of the most striking surface features on Ceres is the small crater Oxo (diameter $\sim 9 \mathrm{~km}$ ), which shows the second highest reflectance on the surface of Ceres. Combe et al. (2016) reported the detection of local $\mathrm{H}_{2} \mathrm{O}$ ice exposures inside the crater by using data from the Visible and Infrared Mapping Spectrometer (VIR; De Sanctis et al. 2011). Combe et al. (2016) found that some spectra at Oxo are most consistent with $\mathrm{H}_{2} \mathrm{O}$ ice, but could also be attributed to hydrated materials. They argue that Oxo is a young crater exposing water-ice. The geological context of Oxo has been described by Hughson et al. (2017). Oxo is embedded in an ancient cratered terrain, which is the most widespread surface unit on Ceres (Buczkowski et al.2016). The geology and morphology of Oxo are mainly defined by the surrounding ejecta blanket, striped crater wall material, mixed crater floor material, and the terrace (Hughson et al. 2017). Its latitude on Ceres places Oxo in a zone sensitive to ice-related processes: while polar latitudes are too cold for a significant mobility of ice, brine, and water, equatorial latitudes are relatively depleted of water or water-ice due to higher temperatures that prevented their preservation (Titus 2015; Schorghofer 2016).

Here, we report our analyses of Oxo's geological evolution using FC and VIR data obtained at the highest available spatial resolutions. These results are also consistent with impactrelated dehydration.

\section{Data Processing and Method}

Dawn FC has imaged the entire illuminated surface of (1) Ceres from several different orbits in 2015 and 2016. Ceres was mapped from Survey, High-Altitude Mapping Orbit (HAMO), Low-Altitude Mapping Orbit (LAMO), and XMO3 orbit at spatial resolutions of $\sim 400 \mathrm{~m}_{\text {pixel }}^{-1}, \sim 140 \mathrm{~m}$ pixel $^{-1}, \sim 35 \mathrm{~m} \mathrm{pixel}^{-1}$, and $\sim 140 \mathrm{~m} \mathrm{pixel}^{-1}$, respectively. Framing Camera images exist in different levels: 1a, 1b, and 1c (color filters only), from which we used level 1b (clear filter) and 1c (color filters). Details of processing FC images are reported in Nathues et al. (2014, 2015b). Level 1b/c data are converted to reflectance (I/F) by dividing the observed radiance by solar irradiance from a normally solar-illuminated Lambertian disk. Color cubes are derived by applying an MPS image processing pipeline as described in Reddy et al. (2012) and Nathues et al. (2014, 2015b). Color cubes are photometrically corrected to standard viewing geometry $\left(30^{\circ}\right.$ incidence, $0^{\circ}$ emission angle, and $30^{\circ}$ phase angle) using Hapke functions (Hapke 2012 and references therein). Starting from the photometric model parameters presented by Reddy et al. (2015), Hapke light-scattering parameters have been iteratively derived from the Approach, Survey, and HAMO mission phases. Iteration 


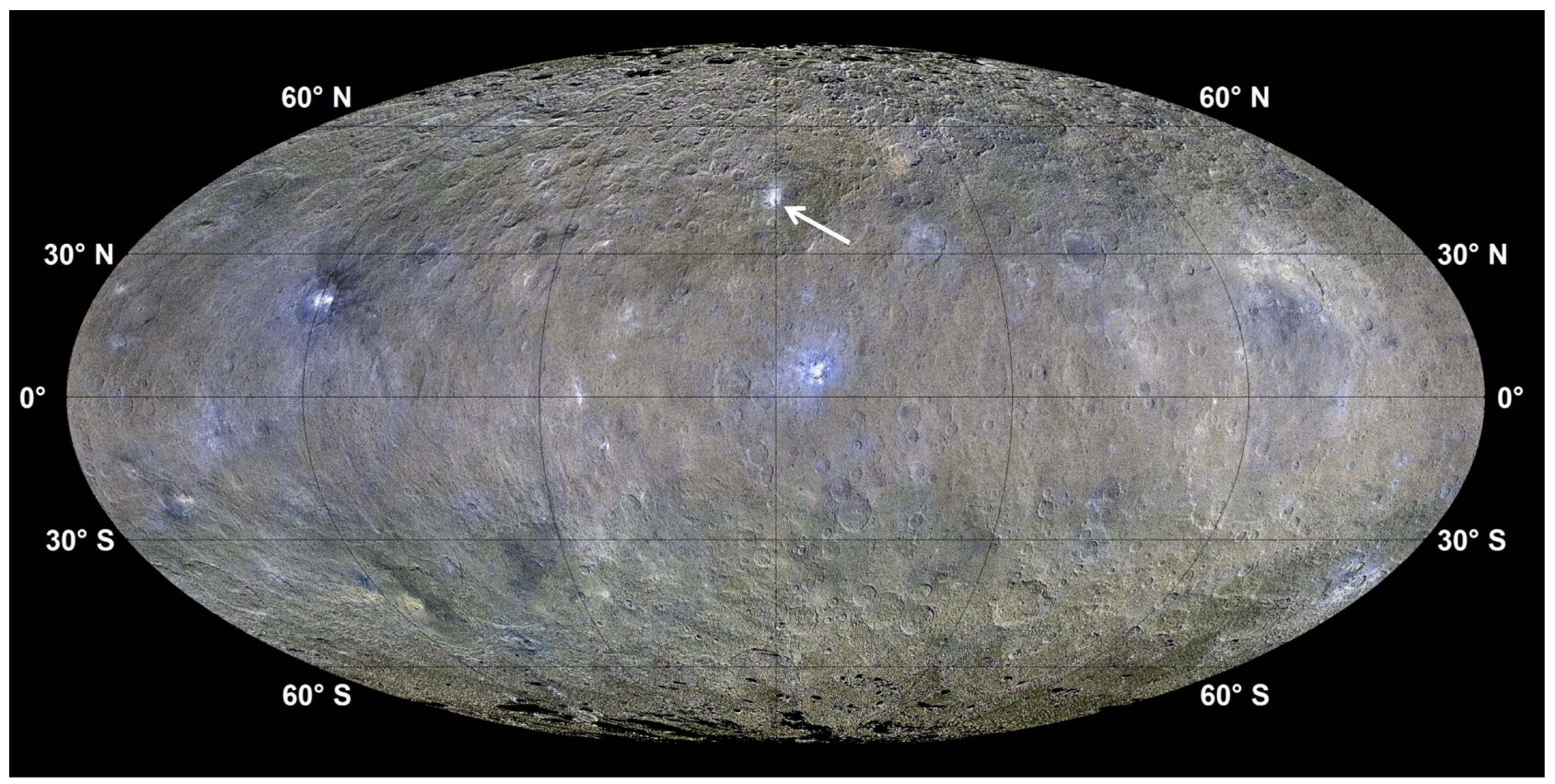

Figure 1. Enhanced color mosaic of the surface of Ceres. Data have been obtained from a distance of $\sim 1400 \mathrm{~km}$ during HAMO and XMO3 orbits. The white arrow marks the location of the Oxo crater, which is the second brightest surface feature on Ceres (Nathues et al. 2015a). The RGB colors are $R=0.96 \mu \mathrm{m}, G=0.75 \mu \mathrm{m}$, and $B=0.44 \mu \mathrm{m}$. The image is a Mollweide projection centered at the prime meridian.

became necessary since increasing resolution leads to increasing significance of subpixel shadows, which change the weight of contributions from different latitudes to a global integrated model fit. For example, a transition from a one-parameter HenyeyGreenstein function to a two-parameter description (Shepard \& Helfenstein 2007) was required for HAMO data. For this correction and the visualization of the results, we used the HAMO Ceres shape model deduced from FC clear-filter stereo images (Preusker et al. 2016). The resulting reflectance data are map-projected in several steps, and co-registered to align the color frames, creating color cubes for our analysis. The cerean surface has also been mapped by the VIR imaging spectrometer covering the wavelength range between 0.25 and $5.0 \mu \mathrm{m}$ (De Sanctis et al. 2011). Radiometrically calibrated and projected VIR reflectance data are available at the Planetary Data System (PDS, https://pds. jpl.nasa.gov/), and were further processed at MPS. In order to allow a comparison with the FC color data, the VIR level $1 \mathrm{~b}$ data were converted to reflectance (I/F) by using the same solar spectrum as for FC data. In a subsequent step, the thermal emission of Ceres was removed by applying a method described in Clark et al. (2011) but adapted for the VIR spectral range. In order to increase the signal-to-noise ratio $(\mathrm{S} / \mathrm{N})$ of the spectra we used averaged spectra. Finally, all spectra were smoothed by a 3 pixel wide boxcar. Due to $\mathrm{S} / \mathrm{N}$ limitations we restricted our analysis of the VIR data to a qualitative analysis, i.e., the presence of diagnostic absorption bands, their shape, and their strength. All FC color and VIR spectral data used in this study have been obtained from LAMO orbit $^{11}$ with resolutions of $\sim 35 \mathrm{~m}$ pixel $^{-1}$ and $\sim 95 \mathrm{~m} \mathrm{pixel}^{-1}$, respectively. The obtained phase angles range between $38^{\circ}$ and $43^{\circ}$ for FC LAMO data and between $52^{\circ}$ and $55^{\circ}$ for VIR LAMO data.

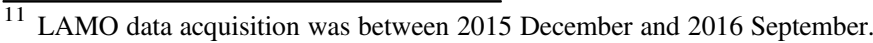

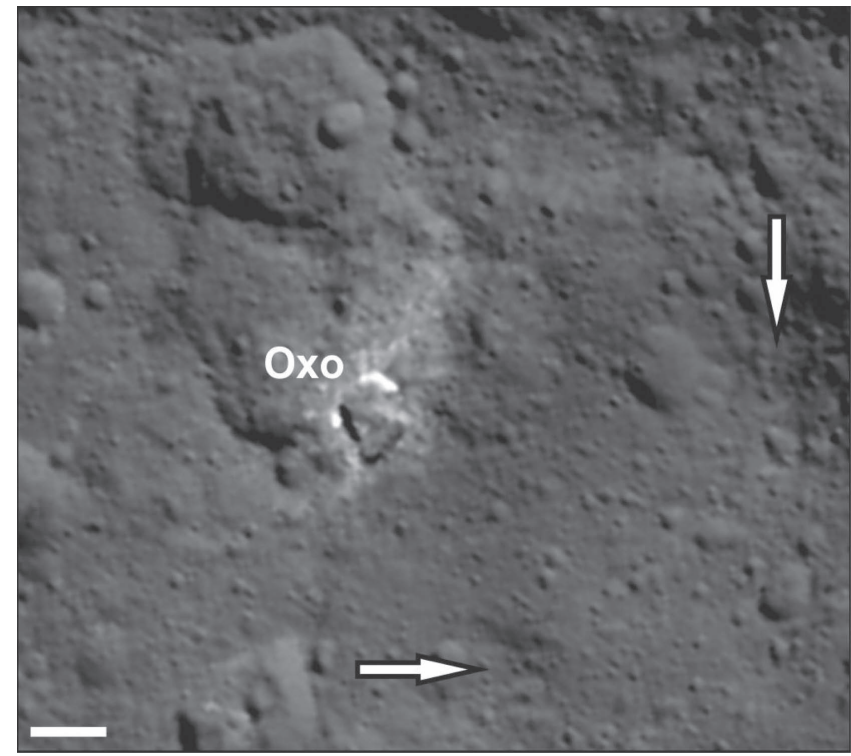

Figure 2. Vicinity of Oxo crater as seen from $\sim 7300 \mathrm{~km}$ distance (detail of the unprojected clear-filter FC image \#37,265 taken during Optical Navigation 8). Oxo is the most recent impact feature of its size on Ceres. Oxo is located offcenter within an older crater, which itself is emplaced in the even older, heavily eroded Duginavi crater (155 km in diameter). Arrows point to two tholi within Duginavi crater: upper right arrow locates Cosecha Tholus; the lower arrow highlights a small unnamed tholus. North points up. The scale bar is approximately $10 \mathrm{~km}$.

\section{Geology of Oxo Crater}

Oxo $\left(42^{\circ} .20 \mathrm{~N}, 359^{\circ} .75 \mathrm{E}\right)$ is a $\sim 9 \mathrm{~km}$ diameter impact crater located on the northern hemisphere of Ceres at the prime meridian (see arrow in Figure 1). With a depth-to-diameter ratio of 0.172 and based on its crater rim and floor morphology, Oxo resembles a transitional complex crater on Ceres (see Hiesinger et al. 2016). Oxo is located on the rim of an 


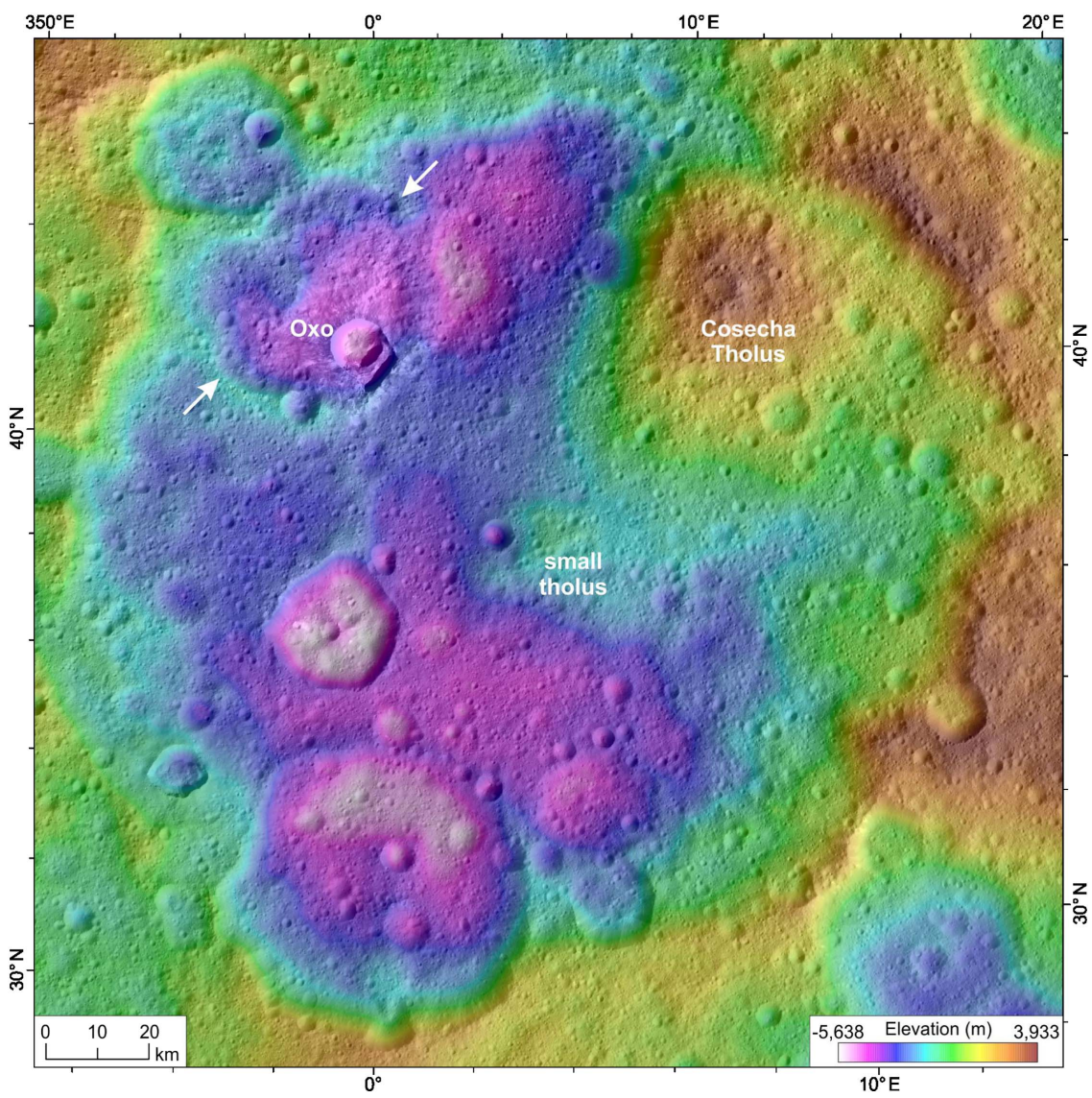

Figure 3. Topographic map of Duginavi crater $(\varnothing \sim 155 \mathrm{~km})$. Oxo is located on the edge of a degraded, $40.5 \mathrm{~km}$ diameter crater (white arrows) in the northwestern portion of Duginavi. Two tholi exist within Duginavi. The summit of Cosecha Tholus rises up to $\sim 3870 \mathrm{~m}$, which is approximately the same height as the degraded northeastern rim of Duginavi. The lowest point $(\sim-5638 \mathrm{~m})$ in Duginavi is within a $19 \mathrm{~km}$ diameter crater about $42 \mathrm{~km}$ south of Oxo. Stereographic projection is centered at the north pole.

unnamed, heavily degraded, $40.5 \mathrm{~km}$ diameter crater, which itself formed within the eroded, $155 \mathrm{~km}$ diameter Duginavi crater centered at $39^{\circ} .2 \mathrm{~N} / 4^{\circ} .3 \mathrm{E}$ (see Figures 2 and 3).

The floor of Oxo is one of the lowest-lying surfaces on the northern hemisphere of Ceres, with an altitude of $-4802 \mathrm{~m}$ below the reference ellipsoid (Figures 3 and 4). Thus the relatively small Oxo impact has excavated subsurface layers significantly deeper than at most sites on Ceres (see below). Aside from some local depressions at equatorial latitudes all sites on Ceres (i.e., northern and southern hemispheres) at elevations below $-4700 \mathrm{~m}$ are associated with impact craters. The lowest point on Ceres is located within Rongo crater (Platz et al. 2017). The geology of Oxo indicates that this is among the youngest craters, based on its crisp rim morphology (where many other crater rims on Ceres are slumping or eroded), welldefined ejecta blanket, and the presence of only a few superimposed craters (see Section 4). In addition, at least 77 boulders $\gtrsim 140 \mathrm{~m}$ in diameter rest on the floor and rim (Hughson et al. 2017), indicating Oxo's youthful age because boulder preservation generally diminishes with time due to destruction by (micro)meteoroidal bombardment.

The formation of the Oxo impact crater on the $\sim 1.5 \mathrm{~km}$ high and up to $20^{\circ}$ steep inner, pole-facing rim of a $40.5 \mathrm{~km}$ diameter degraded crater caused structural post-formation modification of the crater. The current southeastern rim of Oxo (the segment parallel to the contour lines) is dislocated downslope from its original position by $1.1 \pm 0.1 \mathrm{~km}$ in plane view with a vertical offset of about $0.3-0.4 \mathrm{~km}$ relative to the unmodified rim; the effective drop height is estimated to be about $0.5 \mathrm{~km}$ based on an idealized crater rim (see Figure 5(A)). The slumped rim segment appears slightly tilted, which probably resulted from downslope motion along a listric fault plane (see Figures 5(E) and (D)). Scarps on and concentric to the rim segment are noted, which indicate internal fracturing during slumping. Approximately $3.1 \mathrm{~km}$ upslope of the dislocated rim segment a pronounced rectangular main scarp (see Figure 5(A)) is observed as outlined by the $7.7 \mathrm{~km}$ long main scarp and up to $4.4 \mathrm{~km}$ long secondary scarps (Figures 5, 6). The height of the main scarp is up to $1.1 \mathrm{~km}$. The main scarp itself follows the linear rim crest of the $40.5 \mathrm{~km}$ diameter (polygonal) crater. The collapsed material from the nearly rectangular main scarp accumulated at its base, partially burying the collapsed rim segment. Three lobate surface flows within Oxo are observed, originating on the rims and flowing into the base of the main bounding and secondary scarps (see Figure 10). These features are defined by long discrete trunks and steep rounded toes, and thus were classified as "type 1" deposits (Schmidt et al. 2017). Type 1 flows increase in frequency toward the poles and have been interpreted as icerich based on their location and morphology, and likely imply at least 10\% ice (Schmidt et al. 2017). At and below the two tear points (see Figure 5(A)) where the rim segment detached from the intact rim, broad and unconsolidated apron fans and successions of small lobate deposits are observed.

The intact crater wall of Oxo is composed of intermixed bright and dark unconsolidated talus material extending from 


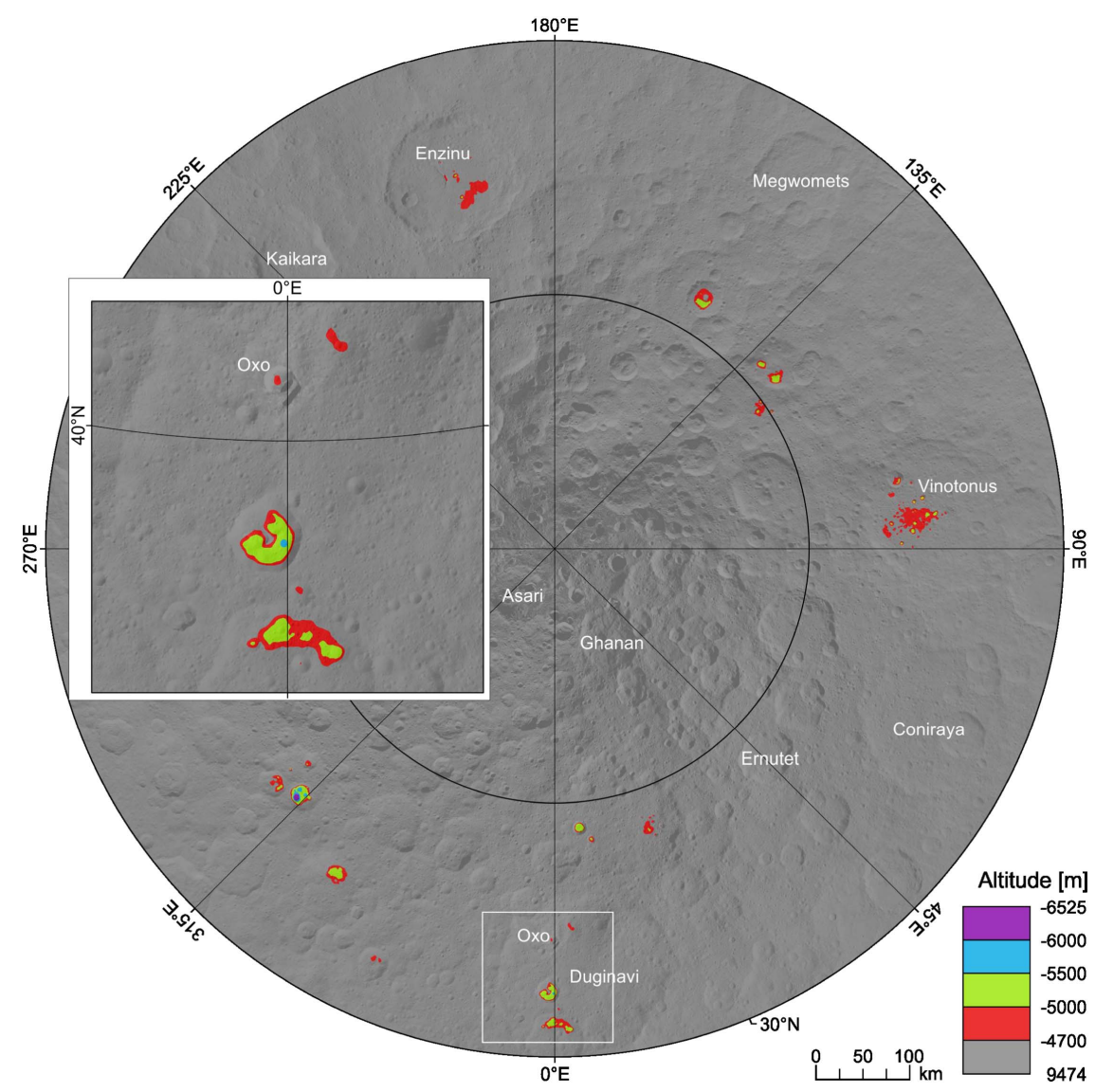

Figure 4. Topography of the northern hemisphere of Ceres poleward of $30^{\circ} \mathrm{N}$. The HAMO Digital Terrain Model is superimposed on the LAMO clear-filter mosaic. All colored sites deviate more than $-4700 \mathrm{~m}$ from the best-fit $482.8 \times 480.6 \times 445.0 \mathrm{~km}$ reference ellipsoid (Preusker et al. 2016). Any location above $-4700 \mathrm{~m}$ altitude is shown in gray. The inset shows portions of Duginavi's crater floor. The lowest point on Oxo's floor is at $-4802 \mathrm{~m}$. Note that the inset shown does not obscure any low-lying sites. Stereographic projection is centered at the north pole.

the rim crest to the crater floor. In places, consolidated outcrops in the upper crater wall are present. At the base of the wall fanshaped debris aprons and lobate deposits are observed, exposing bright and dark material. Smooth and hummocky deposits, upon which large boulders rest, characterize the crater floor.

During the Oxo impact event bright material has been excavated and irregularly distributed within the ejecta material. Individual bright rays as seen in false-color-ratio RGBs (e.g., Figure 7) and photometrically corrected clear-filter mosaics extend up to $22.5 \mathrm{~km}$ from the rim. The smallest extent of the asymmetric ejecta blanket is toward the southeast and likely a consequence of the elevated pre-existing crater rim of the $40.5 \mathrm{~km}$ diameter older crater that blocked the ejecta. The absolute reflectance of bright ejecta material typically reaches $\sim 0.1$ at $0.55 \mu \mathrm{m}$, with maxima at individual sites of up to $\sim 0.25$. Some intact boulders are made of bright material whereas the bright patches near the rim crest may represent partly disintegrated boulders. Outcrops of bright material are observed along the upper crater wall of Oxo including the slipped rim segment and within unconsolidated lobate deposits (Figures 6, 9, and 10). The maximum reflectance of the upper-wall bright material is $\sim 0.24$ at $0.55 \mu \mathrm{m}$. Reflectance values of up to $\sim 0.15$ at $0.55 \mu \mathrm{m}$ are reached at lobate deposit \#1, which shows the strongest water-ice signatures in VIR spectra (Combe et al. 2016; Hughson et al. 2017; Figure 8). The brightest FC pixel of the lobate deposit \#1 (Figure 6) is adjacent to a potential crater that formed here of less than $115 \mathrm{~m}$ in diameter. This small impact may have excavated bright water-ice-rich material (see Section 5). We note that surface water-ice in Oxo is probably excavated as a consequence of small impacts, which cannot be detected at LAMO resolution (i.e., craters less than about $100 \mathrm{~m}$ in diameter are not identifiable in LAMO images).

\section{Crater-based Model Ages}

The age of a planetary surface unit can be estimated by determining the density of impact craters that have accumulated on the unit since its formation (Arvidson et al. 1979; Neukum \& Hiller 1981; Platz et al. 2013). For model age determinations on Ceres the lunar-derived chronology and production functions of Hiesinger et al. (2016) are applied. Crater mapping and statistical analysis of the crater size-frequency distribution were carried out by utilizing CraterTools (Kneissl et al. 2011) and Craterstats (Michael \& Neukum 2010; Michael et al. 2012, 2016), respectively.

Previously, the formation model age of Oxo has been estimated to be between 2.1 and 4.3 Ma (Hughson et al. 2017) and $500 \pm 200 \mathrm{ka}$ (Schmedemann et al. 2016) by measuring the crater population on the ejecta. In this study, we also examined impact craters, which are unambiguously exposed on the ejecta blanket, i.e., they formed after the Oxo impact event. A 3D anaglyph of Oxo has been prepared to identify small impact craters and to clearly distinguish craters and boulders (Figure 10). Only five craters are found to be superimposed on 

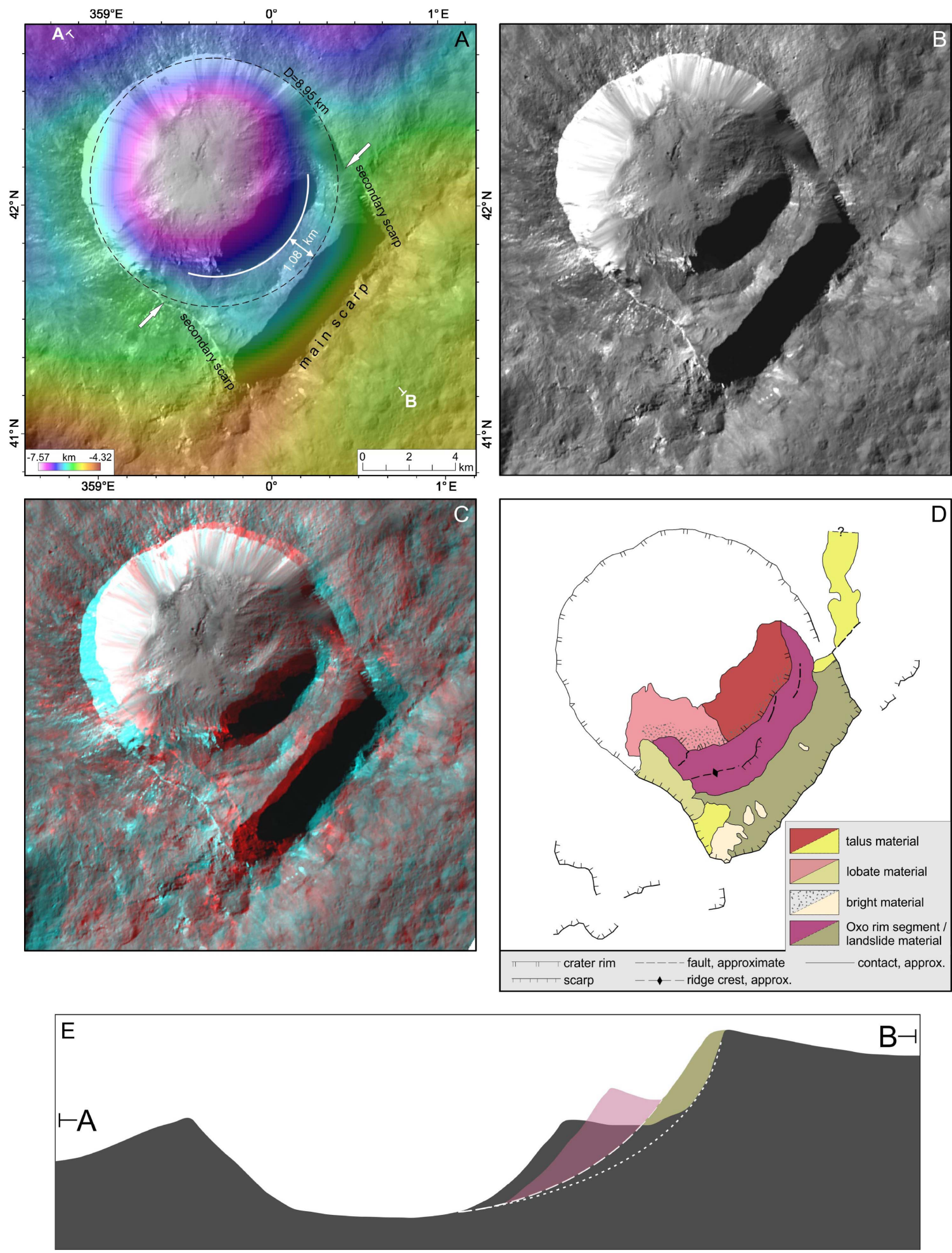

Figure 5. Geological evolution of Oxo crater. (A) The topographic relief of Oxo crater and its immediate vicinity is visualized by superimposing the HAMO-based digital terrain model (Preusker et al. 2016) on FC image 52,044. The best-fit diameter of Oxo is $8.95 \mathrm{~km}$ (dashed circle). The idealized crest of the collapsed rim segment is highlighted as a white arc, which is offset from its inferred position by a distance of $1.08 \mathrm{~km}$ in the plane view. Tear points are marked by white arrows. The pronounced main and secondary scarps upslope of Oxo are highlighted. Locations A and B mark the cross section shown in (E). The image is shown in stereographic projection centered at the north pole. (B) Oxo crater as recorded in FC clear-filter image 52,044. Same scene as in (A). (C) 3D anaglyph of Oxo crater, created from FC images 66,381 and 52,044 with a vertical exaggeration of 3.1 (see Figure 10). Same scene as in (A). (D) Geological sketch of Oxo crater highlighting only structural features and deposits, which are associated with Oxo's rim segment failure (red-toned colors) and the ridge collapse (green-toned colors). Note the lobate deposit originating from a fault on the eastern rim of Oxo extending northward. Its terminus is disguised by superposed ejecta flow deposits. Same scene as in (A). (E) Cross section A-B over a distance of $21.3 \mathrm{~km}$ as shown in panel (A). The dark gray area reflects a slightly modified topographic profile at $2 \times$ vertical exaggeration. The inferred original position of Oxo's intact rim (reddish) and the pre-collapse ridge relief (green) are highlighted. Failure along listric fault planes (white dashed and dotted lines) caused block sliding of the rim segment and landsliding on the ridge. 


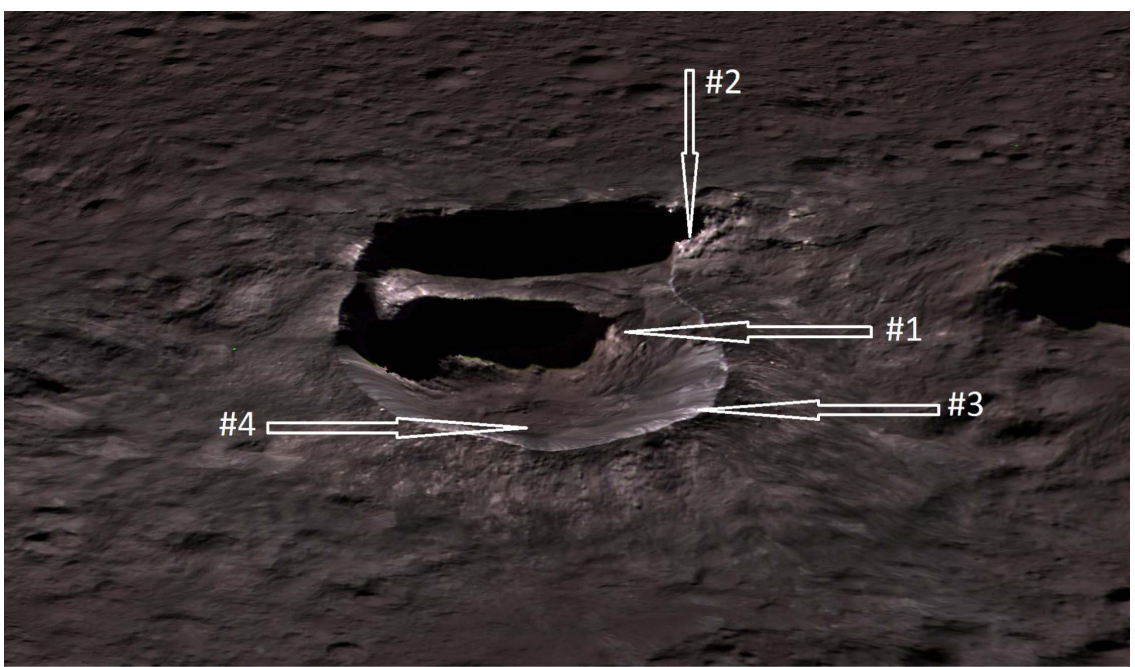

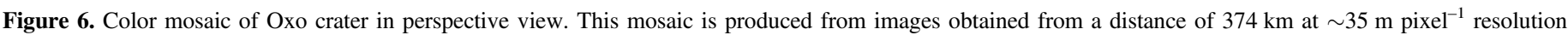

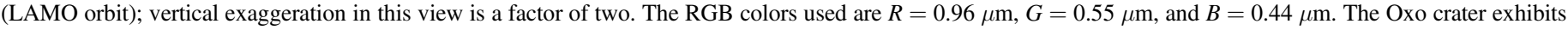

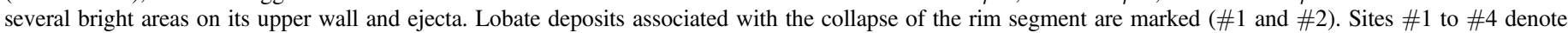
locations from which spectra in Figure 8 have been obtained. The view is toward the southeast.

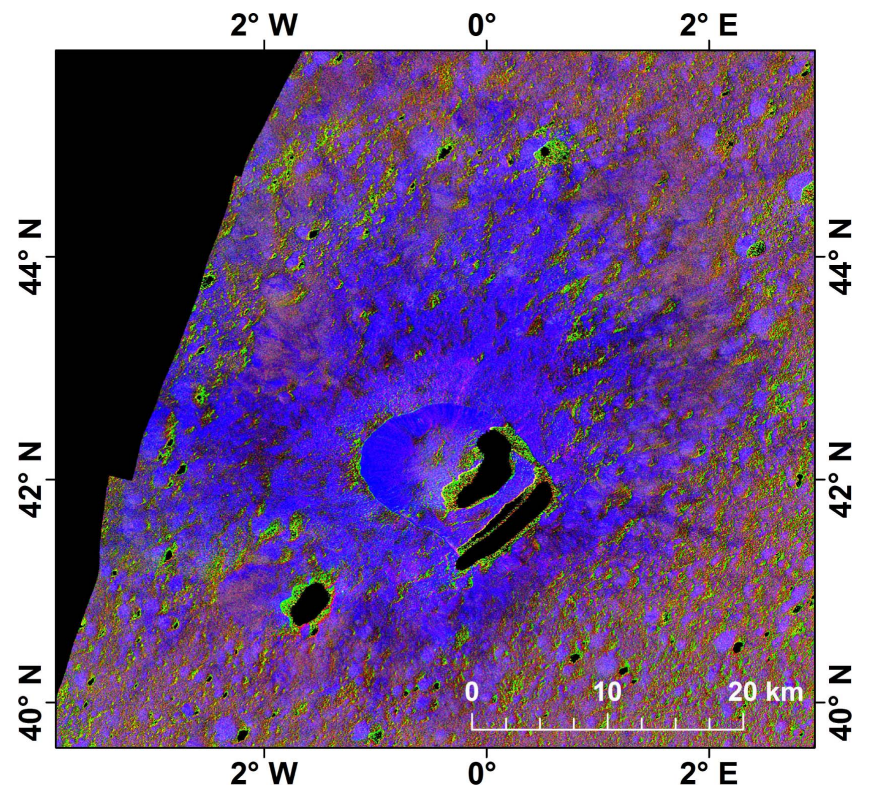

Figure 7. False-color LAMO mosaic of Oxo crater $(R=0.65 \mu \mathrm{m} / 0.43 \mu \mathrm{m}$, $G=0.65 \mu \mathrm{m}, B=0.96 \mu \mathrm{m} / 0.65 \mu \mathrm{m}$ ) highlighting the bright ejecta (in violet to blue colors).

proximal to medial ejecta material. The resulting model age for the Oxo formation event is (only) $190 \mathrm{ka}(1 \sigma:+100 \mathrm{ka}$, $-70 \mathrm{ka}$ ) (Figure 11). The main reason for the difference in model age between our estimate and the age given by Hughson et al. (2017) is that they counted all craters within the mapped area of the ejecta including partially buried craters. Although this approach is required for crater-based dating of geological units (see Platz et al. 2013), it causes problems where a cratered surface is not homogeneously resurfaced, i.e., the crater ejecta thins with increasing distance from the rim. As a result, it becomes difficult at distal reaches of the ejecta to distinguish an impact crater from being lightly mantled or being superimposed on the ejecta.

\section{Spectral Properties and Composition}

For the present analysis we investigated FC color cubes as well as VIR cubes covering the wavelength ranges $0.4-1.0 \mu \mathrm{m}$ and $1.0-4.2 \mu \mathrm{m}$, respectively. In order to identify compositional differences, we analyzed spectra of several sites at Oxo and compared these sites with the global average spectrum of Ceres (Figure 8). Framing Camera high-resolution color imagery resolves differences in material properties (e.g., albedo) of Oxo's morphological features (Figure 6). However, these visible to near-infrared spectral data do not cover diagnostic cerean absorption features and thus are not shown here.

We have identified four sites at Oxo crater that differ spectrally in the 1.0-4.2 $\mu \mathrm{m}$ wavelength range (Figure 8). Two sites exhibit prominent water-ice absorption bands at $\sim 1.5$ and $\sim 2.0 \mu \mathrm{m}$ (spectra \#1 and \#2 in Figure 8) as well as the weaker $1.65 \mu \mathrm{m}$ band due to crystalline water-ice, which are associated with two lobate deposits on the southern main and secondary scarps (Figure 6). As discussed by Combe et al. (2016), these absorption features are superficially more consistent with the presence of water-ice, but could in principle also be due to mixtures of hydrated minerals.

The northern and western upper crater walls show the highest reflectance values (up to $\sim 0.24$ at $0.55 \mu \mathrm{m}$ at LAMO resolution) at Oxo in FC data. The associated VIR spectra (e.g., \#3, Figure 8) are characterized by negative spectral slopes throughout the range 1.0 to $\sim 4.0 \mu \mathrm{m}$. Similar spectral slopes are found in bright ejecta materials covering mainly the area northeast of Oxo (Figure 2) but are also prevalent at other sites. The bright material at Oxo in FC colors is similar to that found at other young craters on Ceres, e.g., at Haulani and Occator, even if Oxo's ejecta are less thick (Schmedemann et al. 2016). Mixing-model analyses at Occator crater suggest a varying composition including phyllosilicates (background material) and carbonates (De Sanctis et al. 2016); the higher the albedo the larger is the carbonate component. However, the results of mixing models derived by De Sanctis et al. (2016) need to be confirmed by experimental studies of minerals/ice mixtures measured at relevant temperatures, and should be used with 


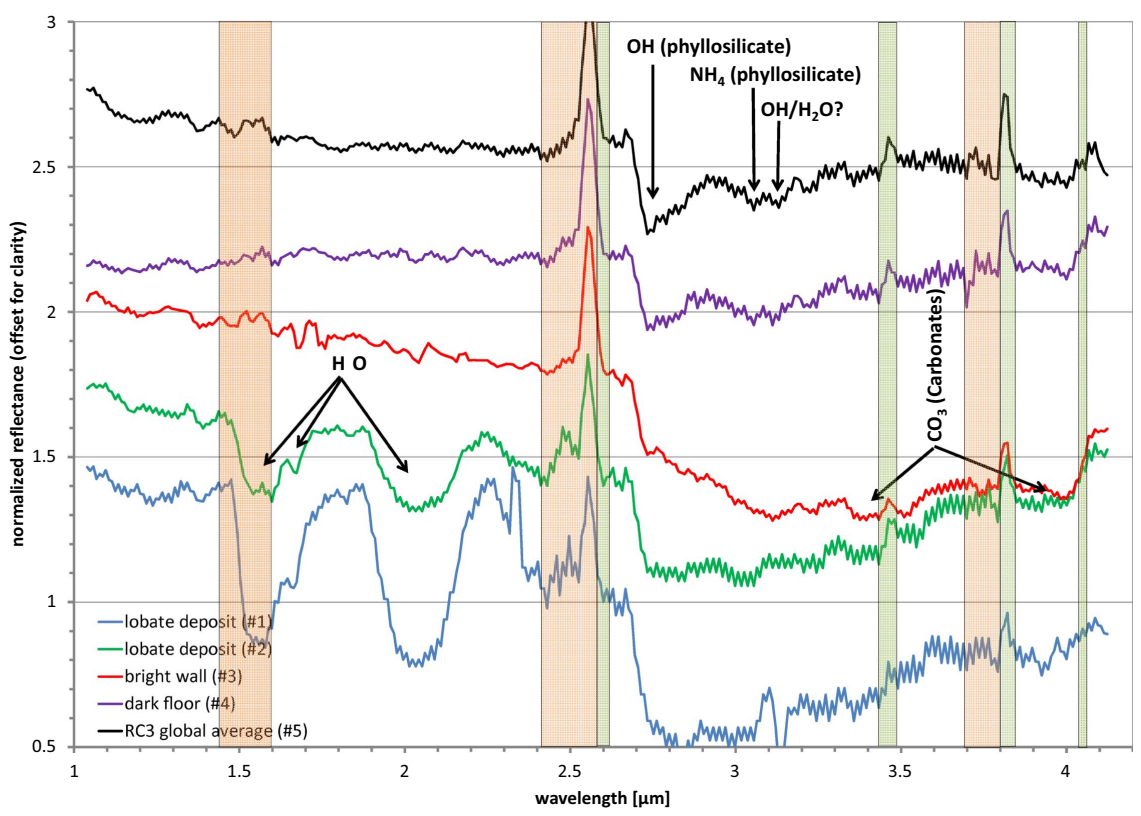

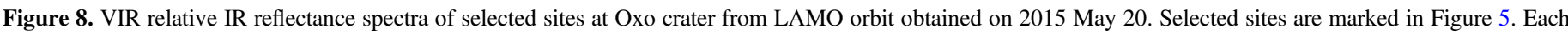

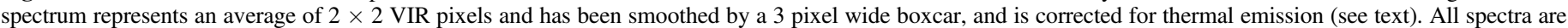

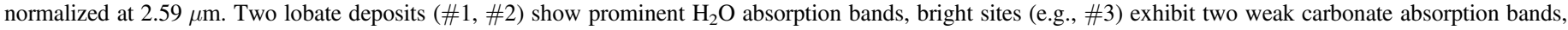

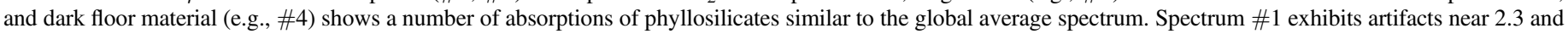
$3.1 \mu \mathrm{m}$. Pink boxes mark wavelength ranges that are strongly influenced by order-sorting filters on the instrument. Green boxes mark artifacts in the data.

caution for the time being. Due to the presence of the $\sim 3.9 \mu \mathrm{m}$ carbonate absorption feature in spectra of the bright Oxo sites (e.g., spectrum \#3, Figure 8) it can be inferred that carbonates are also present at these sites. We found many bright patches on Oxo's upper wall and ejecta and some less bright areas associated with the lobate deposits \#1 and \#2 (Figure 6), which show prominent water absorption bands.

Dark material is also present in and around Oxo but often admixed with bright material, showing an increased average reflectance $>0.04$ at $0.55 \mu \mathrm{m}$ of the Oxo area, compared to $\sim 0.03$ at $0.55 \mu \mathrm{m}$ of the average cerean surface (Nathues et al. 2015a). Spectra of dark material (e.g., spectrum \#4 in Figure 8) show evidence of ammoniated phyllosilicates, as was found on a global scale by De Sanctis et al. (2015). Lowest reflectances, $<0.03$ at $0.550 \mu \mathrm{m}$, are found on the northern floor of Oxo, and the inhomogeneous distribution can be attributed to the relocation of material by the cratering events predating the Oxo impact. The large difference in reflectance between dark and bright material at Oxo is remarkable, making Oxo distinct from all other recently formed small craters on Ceres. Reflectances of $\sim 0.2$ at $0.55 \mu \mathrm{m}$ are significantly higher than expected for coarse-grained pure water-ice (grain size in the millimeter range; Clark 1981), which also suggests that the bright patches exposed on the upper crater wall and within the ejecta are not composed of exposed water-ice bedrock or boulders. Instead, spectra of these sites (\#1 and \#2) show an absorption band at $\sim 3.9 \mu \mathrm{m}$ that is attributed to carbonates. Thus the high albedo of the bright sites at and around Oxo is likely associated with bright carbonates. Spectra of the lobate deposits (spectra \#1 and \#2 in Figure 8), however, clearly show two water absorption features at $\sim 1.5$ and $\sim 2.0 \mu \mathrm{m}$. Both the shape of the $\sim 2.0 \mu \mathrm{m}$ absorption feature and the relative depths of the $\sim 1.5$ and $\sim 2.0 \mu \mathrm{m}$ features indicate that the present waterice is not coarse-grained. If it were, one or both of these bands would be optically saturated, leading to these bands having similar depths and a broadening of the $\sim 2.0 \mu \mathrm{m}$ band, due to optical saturation that can occur for large transparent particles. Thus the bright patches associated with the southwestern secondary scarp are likely mixtures of carbonates with significant amounts of water-ice and dark background material. The ice-rich site \#1 exhibits reflectances between $\sim 0.07$ and $\sim 0.15$ at $0.55 \mu \mathrm{m}$.

Oxo images from LAMO orbit show the entire main scarp and portions of the two secondary scarps in shadow (Figure 9(A)). In order to inspect these shaded areas at the highest spatial resolution we searched for albedo variations seen in multiply scattered light (see Figure 9(D)) and potential temporal changes of these over the eight-month imaging campaign. We did not find obvious changes in albedo with time in those areas. However, in multiply scattered light the scarps show an albedo contrast of up to $50 \%$ (Figure 9(D)).

\section{Discussion}

Shortly after the arrival of Dawn at Ceres, an unusual lightscattering behavior at Oxo crater was observed in FC images obtained during Rotation Characterization 3 (Nathues et al. 2015a). This effect was attributed to a potential local haze development in "Feature A" (preliminary name of Oxo crater). The detection of diagnostic water absorption bands in VIR spectra and the inferred sublimation of water-ice supported this interpretation (Combe et al. 2016). What makes Oxo crater so special? To address this question we performed a comprehensive investigation to decipher the geological evolution of Oxo and its vicinity, as well as placed Oxo into the global context.

The pristine crater rim morphology and the well-preserved ejecta blanket with its characteristic diffuse and smooth surface texture indicate that Oxo is a very young impact structure. The presence of only a handful of superimposed craters on its ejecta material supports a youthful age of $190 \mathrm{ka}(1 \sigma:+100 \mathrm{ka},-70 \mathrm{ka})$. 

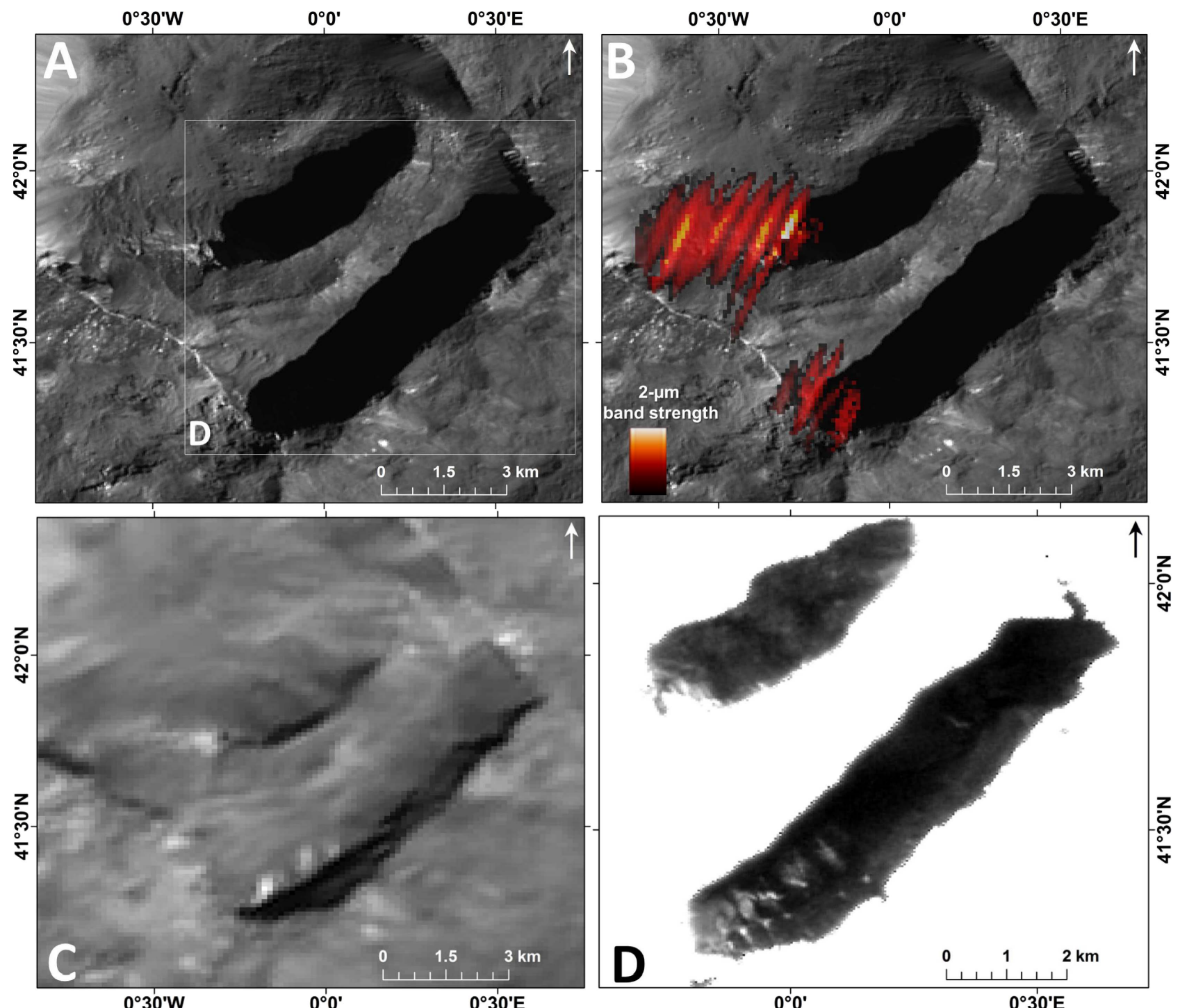

Figure 9. Images of Oxo crater in the clear filter. (A) LAMO FC image \#58,506 shows the southern portion of Oxo crater. (B) Same scene as in (A) but now with a colorized ratio $(1.84 \mu \mathrm{m} / 2.02 \mu \mathrm{m})$ superimposed that is diagnostic of the strength of the $\sim 2.0 \mu \mathrm{m} \mathrm{H}_{2} \mathrm{O}$ absorption band. The LAMO VIR data are smeared due to spacecraft motion. The lower left portions of the VIR trails match the respective features seen in FC data. The water absorptions are associated with bright patches at both lobate deposits \#1 and \#2 (see Figure 6). (C) HAMO FC image \#42,450 showing the same scene as in (A). Shadows are smaller in HAMO than in LAMO imagery because the former were taken closer to northern summer solstice. Thus larger fractions of the pole-facing slopes are illuminated in HAMO images, including bright material at sites \#1 and \#2. (D) Multiply scattered light reveals several bright deposits at the lower western main scarp. Due to the strong water absorption features of sites \#1 and \#2 it can be inferred that all these bright sites exhibit water-ice.

Excavated bright materials distributed throughout the ejecta blanket show characteristic bright-to-bluish colors in FC images (Schmedemann et al. 2016) and represent a further line of evidence for an optically less matured material, as has also been observed at other young craters on Ceres, e.g., Haulani and Occator (Nathues et al. 2016, 2017; Schmedemann et al. 2016; Stephan et al. 2017).

The formation of Oxo crater occurred on a pole-facing slope of a linear, northeast-southwest trending ridge, which represents a segment of a degraded, polygonal crater $40.5 \mathrm{~km}$ in diameter. This degraded crater developed on the northwestern floor of the older heavily degraded, $155 \mathrm{~km}$ diameter crater Duginavi (Figures 2 and 3). Upslope of Oxo crater a prominent rectangular scarp is observed, which was interpreted as bounding scarps of a large terrace slump block (Hughson et al. 2017). Although this interpretation was reasonable on the basis of analysis using the HAMO-based digital terrain model (DTM), it differs substantially from our interpretation. This
DTM with its lower resolution $\left(\sim 137 \mathrm{~m} \mathrm{pixel}^{-1}\right)$ does not adequately represent the morphology of Oxo as seen in LAMO FC images $\left(\sim 35 \mathrm{~m} \mathrm{pixel}^{-1}\right)$. In a southeast-looking perspective view (see Figure 6), a large terrace block can be easily seen. However, the absence of impact craters superimposed on this terrace as noted by Hughson et al. (2017) disagrees with block slumping of a densely cratered ridge. Observing and describing a given landform in detail can only be achieved by using highest resolution, three-dimensional anaglyphs based on stereo image pairs (Figure 10). Our interpretation of the main aspects of the evolution of Oxo crater is highlighted in Figures 5 and 12 .

On Ceres there are many examples where impact craters exhibit linear or rectangular scarps as consequence of wall or rim failure (e.g., Schmidt et al. 2017; Figure 12). The resulting unconsolidated, lobate to fan-shaped deposits form hummocky to smoothtextured surfaces. Our initial survey shows that these linear scarps 

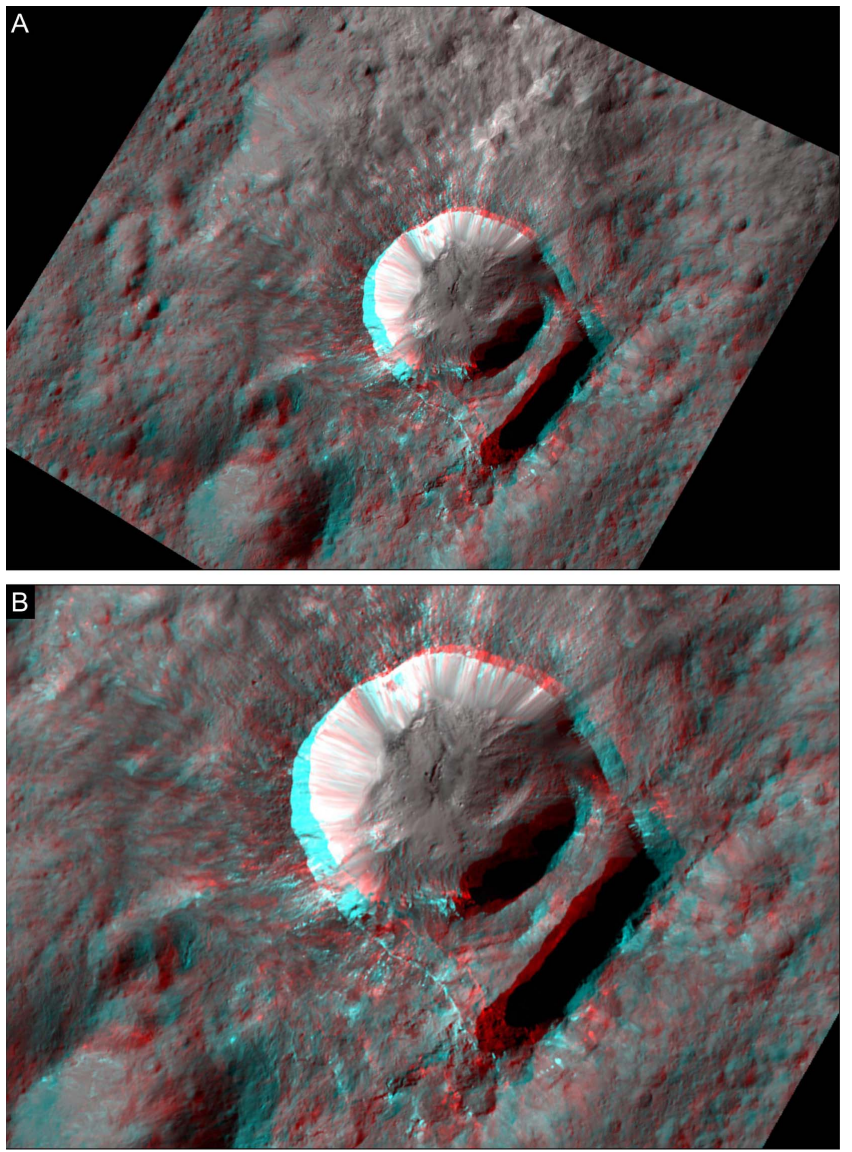

Figure 10. 3D anaglyph of Oxo crater. (A) and (B) show Oxo at different magnifications. The anaglyph is created from the FC clear-filter images 66,381 and 52,044 using a local radius of $460.065 \mathrm{~km}$ to retain high- and lowfrequency stereo data. The vertical exaggeration is 3.1 .

develop when an impact crater is formed on a pre-existing crater rim or ridge (Figures $12(\mathrm{C})-(\mathrm{J})$ ). A qualitative assessment suggests that crater wall failure is initiated when the transient cavity fully breaches the pre-existing rim, i.e., syn-formation wall failure (Figures 12(C) and (I)). On the other hand, rim failure appears to be induced when the transient cavity is only tangent to the preexisting rim crest, causing its collapse toward the pre-existing crater floor (Figures 12(E) and (G)). There are a number of transitional complex and complex craters exhibiting syn- or post-formation wall collapse, causing their typical scalloped rim outline. One example is the moderately degraded Rao crater (Figure 12(A)). Here a small segment of the eastern wall collapsed. The failed arc segment is partially preserved as a coherent block on the crater floor. It travelled a distance of approximately $3.7 \pm$ $0.1 \mathrm{~km}$ (in plane view) with a drop height of about $1.4 \mathrm{~km}$.

The collapse history at Oxo crater is even more complex. The southeastern crater rim of Oxo, spanning nearly half the diameter, failed and slipped downslope toward the center of the crater floor. The confinement of the steep crater walls inhibited sliding along a listric fault plane closer to the crater's center. The estimated plane-view offset and drop height are $1.1 \pm$ $0.1 \mathrm{~km}$ and approximately $0.4 \mathrm{~km}$, respectively (Figure 5). Although the failed rim segment appears intact, it did experience fracturing, as evidenced by the presence of faults and ridges (Figure 5(D)). At the end points of the failed rim, talus and lobate deposits formed, including mass-wasting of wall material close to the tear points. Bright material is exposed along the upper pole-facing slope of the failed rim and is partially intermixed within lobate deposits on its upper slope, where water-ice signatures were detected.

The rectangular scarp upslope of Oxo crater consists of the $7.7 \mathrm{~km}$ long main scarp and its bounding secondary scarps. Their formation is a consequence of mass-wasting that occurred after or was triggered by Oxo's rim failure. Either way, the deposition of collapsed material is confined to the area defined by the scarps and the displaced rim segment (and likely partially burying it) (Figure 5). Lobate deposits are observed along the secondary scarps. The bright material detected in multiply scattered light within the main scarp's shadow may also be associated with lobate deposits akin to those observed at the lower rim segment (Figure 9) where water-ice absorption bands are detected in VIR data by Combe et al. (2016) and in the present work. Exposures of water-ice along pole-facing slopes suggest lower sublimation rates due to a weaker solar irradiance compared to Sun-facing or flat surfaces. Typical maximum surface temperatures at the latitude of Oxo are about $210 \mathrm{~K}$ (Hayne \& Aharonson 2015), which is consistent with those values derived when using the thermal removal approach of Clark et al. (2011). According to Landis et al. (2017) exposed surface ice only remains bright (sublimation lag formation) for a period of a few years. The bright carbonate outcrops on the upper wall and the bright carbonate ejecta material of Oxo have likely already lost most or all of any preexisting water-ice.

We expect that the water-ice at Oxo originates from early Ceres after its differentiation. Ceres formed a rocky core of hydrated silicates and an ice-rich outer shell (e.g., McCord \& Sotin 2005; Park et al. 2016). Water-ice is unstable on the surface of Ceres; it rapidly sublimates, especially at its equator (Hayne \& Aharonson 2015). However, in the subsurface, water-ice is more stable over time, especially with increasing depth and latitude (Titus 2015), and it may be stable at the surface near the poles. Thus, we can assume that between an ice-depleted near-surface layer and deeper subsurface regions a transition zone exists at which fluidization and evaporation (if exposed) of water-ice occurs. In this zone, admixed salts may further lower melting temperatures and remain as residues in subsurface regolith/dark material. At their place of deposition, residual salts and residual organic compounds form a cementation zone in the layer of hydrated silicate minerals. This process strengthens the uppermost regolith layer, thereby contributing to the development of steep flanks. Depending on the local composition of the near-surface and subsurface material, various aqueous/hydrothermal processes are expected to be triggered by impacts (e.g., Howard et al. 2005; Mangold et al. 2012; Irwin 2013; Newsom et al. 2015). Subsequent impacts will lead to new phenomena depending on the icecontent in the impact area and its topography (Howard 1990).

Oxo is located in an old impact crater named Duginavi that is heavily degraded. This large impact has likely exposed much of the presumed subsurface ice in the past, and thus has led to subsequent depletion of water-ice in exposed and near-surface layers. Later on, several intermediate-size impactors crashed into the old crater, further contributing to the process of water depletion. The irregular crater walls, collapses, and flow features associated with medium-sized craters within Duginavi indicate 

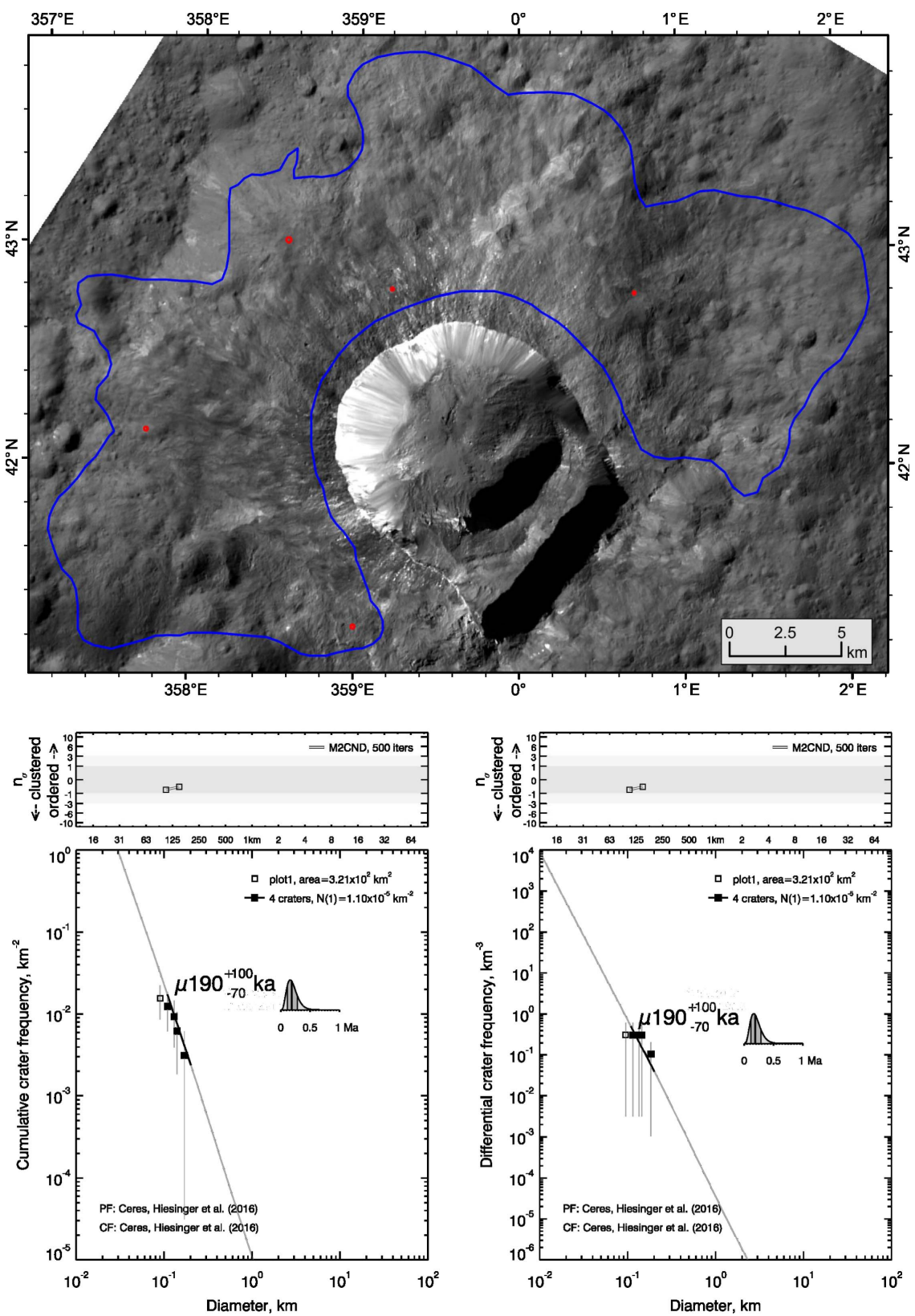

Figure 11. Crater-based model age for the formation of Oxo crater. The upper panel shows the outline of the counting area (in blue), which is solely confined to proximal to medial ejecta material. Only five craters (red outline) are found to be superimposed on the ejecta. The crater size-frequency distribution, as shown in reverse cumulative (lower left) and differential (lower right) graphs plotted against binned crater diameters, yields a model age of $190 \mathrm{ka}(1 \sigma:+100 \mathrm{ka} ;-70 \mathrm{ka})$. The panels above the graphs represent the randomness analysis using the method of the mean distance to the second closest neighbor (Michael et al. 2012).

that surface mobility remained: the crater walls must still hold significant amounts of water-ice. We found that Oxo is predestined to show water-ice because (1) the scarps are located at great depth and (2) Oxo and its scarps containing water-ice are very young. The carbonate content of the bright upper wall and ejecta is also an indication of past hydrous reactions. They remained after impact, while the water-ice sublimated away.

Reflectance, spectral shape, and geological setting of the bright sites at the lobate deposits (\#1 and \#2 in Figure 6) imply a mixture of different amounts of water-ice with carbonates contaminated with some background material. After excavation of the ice, the sublimation process could have generated voids or weakened formerly ice-rich materials, leading to or enhancing collapses at Oxo's original southern wall.

\section{Conclusion}

Oxo is a transitional complex crater of $\sim 9 \mathrm{~km}$ diameter located at the rim of a larger, older crater. Oxo's floor is at a depth of $-4802 \mathrm{~m}$ below the reference ellipsoid and thus is one of the lowest-lying surfaces in the northern hemisphere of Ceres. Its depth and young age of only $190 \mathrm{ka}(1 \sigma:+100 \mathrm{ka}$, $-70 \mathrm{ka})$ favor the presence of near-surface water-ice, which is exposed at two lobate deposits on pole-facing scarps. Water depletion at these sites is ongoing. The water-ice-rich material shows prominent absorption bands at $\sim 1.5$ and $\sim 2.0 \mu \mathrm{m}$ and absolute reflectances of about 0.1 at $0.55 \mu \mathrm{m}$. Ejecta and upperwall bright material show a clear $\sim 3.9 \mu \mathrm{m}$ carbonate feature coupled with absolute reflectances higher than those of the water-ice-rich material, leading to the conclusion that these 

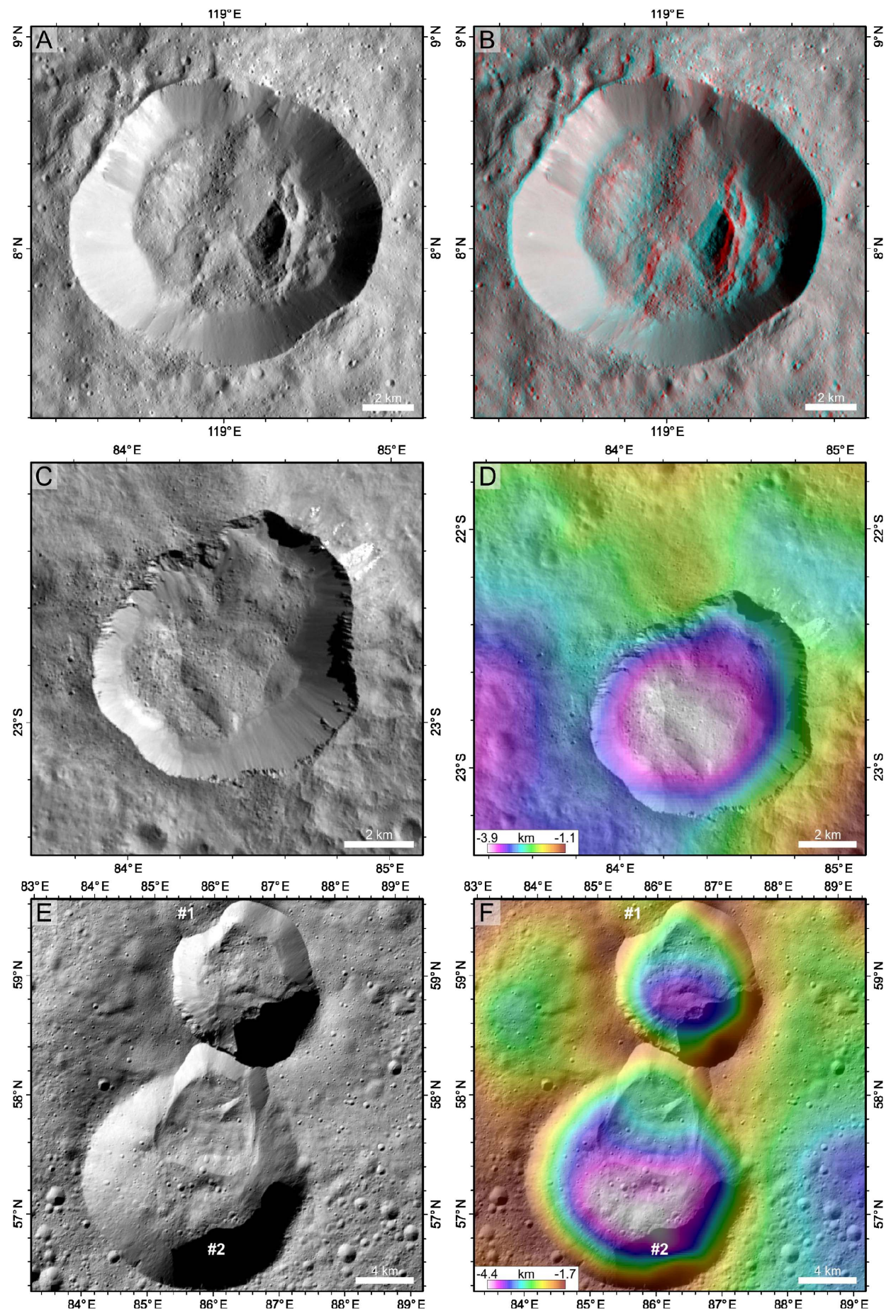

Figure 12. Crater rim collapse features on Ceres. A-B: $12 \mathrm{~km}$ diameter Rao crater in the clear-filter image 47,688 (A) and as a 3D anaglyph (B). A small segment of the eastern rim of Rao collapsed. The arcuate block located on the floor travelled for a distance of $3.7 \mathrm{~km}$ (plane view); the drop height is about $1.4 \mathrm{~km}$. The anaglyph is composed of FC images 47,688 and 68,791; the vertical exaggeration is 2.6. Stereographic projection centered at 8.2 N/119.0 E. C-D: $8 \mathrm{~km}$ diameter Braciaca crater (C) formed on a low-relief ridge (D). The northeastern rim collapsed, forming a linear headscarp (main scarp). The collapsed material fully disintegrated, forming a hummocky deposit with boulders on its surface; the deposit can be traced from the crater floor to the base of the scarp. Similarly, a portion of the southeastern rim segment collapsed. FC image 64,619 (stereographic projection centered at 22.7 S/84.40; E). E-F: The $9.9 \mathrm{~km}$ diameter crater (upper crater in E and F) has a modified rim outline as the result of its formation on two pre-existing crater rims-a smaller $8.8 \mathrm{~km}$ diameter crater (label \#1) causing failure of its northern rim and a larger $15.3 \mathrm{~km}$ diameter crater, where a larger rim collapse occurred with an approximately linear headscarp. In the latter case, rim material disintegrated, forming a well-developed landslide deposit. Spreading of the deposits at its distal reaches is the result of the confinement of the crater floor. FC image 66,267 (stereographic projection centered at $58.4 \mathrm{~N} / 86^{\circ} .3 \mathrm{E}$ ). G-H: A similar setting to that shown in E-F where the younger, $10.2 \mathrm{~km}$ diameter crater formed on the rim of the pre-existing $12.6 \mathrm{~km}$ diameter crater. FC image 53,483 (stereographic projection centered at $58^{\circ} .3 \mathrm{~N} / 56^{\circ} 3 \mathrm{E}$ ). I-J: A similar setting to that shown in E-H where a $9.5 \mathrm{~km}$ diameter crater formed on the pre-existing $10.2 \mathrm{~km}$ diameter crater. Here, however, the rim failure occurred toward the floor of the younger crater. FC image 57,399 (stereographic projection centered at $22.5 \mathrm{~N} / 166^{\circ} 4 \mathrm{E}$ ). K-L: Large failure of a rim segment of Kupalo crater (diameter: $26 \mathrm{~km}$ ) probably triggered by the formation of the $20 \mathrm{~km}$ diameter Juling crater. The linear headscarp is about $14.1 \mathrm{~km}$ long; the northern secondary scarp has a similar extent in plane view. Note several collapse features with the landslide deposit. FC mosaic in stereographic projection centered at $39^{\circ} .1 \mathrm{~S} / 170^{\circ} .2 \mathrm{E}$. 

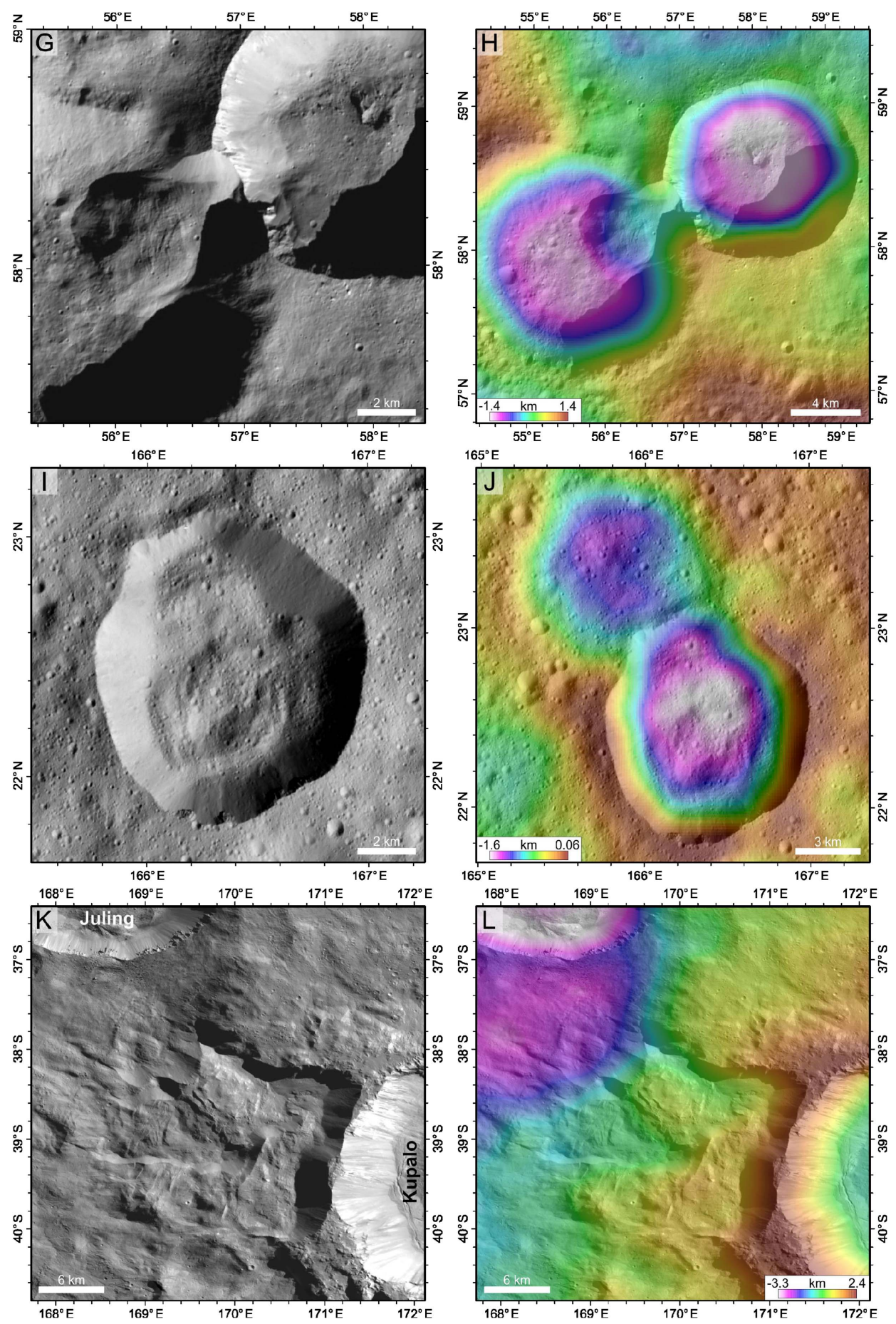

Figure 12. (Continued.)

bright sites at Oxo are mainly mixtures of carbonates and dark phyllosilicates. At those two lobate deposits a mixture of carbonates, water-ice, and phyllosilicates must be present. The Dawn spacecraft will orbit and monitor Ceres closer to perihelion passage, and thus, increased activity due to sublimation processes might become verifiable, as inferred by Küppers et al. (2014).

We thank the Dawn operations team for the development, cruise, orbital insertion, and operations of the Dawn spacecraft at Ceres. Also we would like to thank the Framing Camera operations team, especially P. G. Gutierrez-Marques, J. Ripken, I. Hall, and I. Büttner. The Framing Camera project is financially supported by the Max Planck Society and the German Space Agency, DLR.

\section{References}

Arvidson, R. E., Boyce, J., Chapman, C., et al. 1979, Icar, 37, 467

Buczkowski, D. L., Schmidt, B. E., Williams, D. A., et al. 2016, Sci, 353, aaf4332

Clark, R. N. 1981, JGR, 86, 3074

Clark, R. N., Pieters, C. M., Green, R. O., et al. 2011, JGR, 116, E00G16 
Combe, J.-P., McCord, T. B., Tosi, F., et al. 2016, Sci, 353, aaf3010

De Sanctis, M. C., Ammannito, E., Raponi, A., et al. 2015, Natur, 528, 241

De Sanctis, M. C., Coradini, A., Ammannito, E., et al. 2011, The Dawn Mission to Minor Planets 4 Vesta and 1 Ceres (1st ed.; New York: Springer) De Sanctis, M. C., Raponi, A., Ammannito, E., et al. 2016, Natur, 536, 54

Hapke, B. 2012, Theory of Reflectance and Emittance Spectroscopy (Cambridge: Cambridge Univ. Press)

Hayne, P. O., \& Aharonson, O. 2015, JGR, 120, 1567

Hiesinger, H., Marchi, S., Schmedemann, N., et al. 2016, Sci, 353, aaf4758

Howard, A. D. 1990, Rep. Planet. Geol. Gephys. Program, NASA Tech.

Memo.4210, 342, https://erode.evsc.virginia.edu/papers/howard_ground water_89.pdf/

Howard, A. D., Moore, J. M., \& Irwin, R. P., III 2005, JGR, 110, 1

Hughson, K. H. G., Russell, C. T., Williams, D. A., et al. 2017, Icar, submitted Irwin, R. P., III 2013, LPSC, 44, 2958

Kneissl, T., van Gasselt, S., \& Neukum, G. 2011, P\&SS, 59, 1243

Küppers, M., O'Rourke, L., Bockelée-Morvan, D., et al. 2014, Natur, 505, 525

Landis, M. E., Byrne, S., Schorghofer, N., et al. 2017, LPSC, 1964, 1647

Mangold, N., Kite, E. S., Kleinhans, M. G., et al. 2012, Icar, 220, 530

McCord, T. B., \& Sotin, C. 2005, JGR, 110, E5

Michael, G. G., Kneissl, T., \& Neesemann, A. 2016, Icar, 277, 279

Michael, G. G., \& Neukum, G. 2010, E\&PSL, 294, 223

Michael, G. G., Platz, T., Kneissl, T., \& Schmedemann, N. 2012, Icar, 218, 169

Nathues, A., Hoffmann, M., Cloutis, E. A., et al. 2014, Icar, 239, 222

Nathues, A., Hoffmann, M., Platz, T., et al. 2016, P\&SS, 134, 122
Nathues, A., Hoffmann, M., Schäfer, M., et al. 2015a, Natur, 528, 237

Nathues, A., Hoffmann, M., Schäfer, M., et al. 2015b, Icar, 258, 467

Nathues, A., Platz, T., Thangjam, G., et al. 2017, AJ, 153, 12

Neukum, G., \& Hiller, K. 1981, JGR, 86, 3097

Newsom, B. H. E., Mangold, N., Kah, L. C., et al. 2015, Icar, 249, 108

Park, R. S., Konopliv, A. S., Bills, B. G., et al. 2016, Natur, 537, 515

Platz, T., Michael, G., Tanaka, K. L., et al. 2013, Icar, 225, 806

Platz, T., Nathues, A., Sizemore, H. G., et al. 2017, Icar, submitted

Preusker, F., Scholten, F., Matz, K.-D., et al. 2016, LPSC, 47, 1954

Reddy, V., Li, J.-Y., Gary, B. L., et al. 2015, Icar, 260, 332

Reddy, V., Nathues, A., Le Corre, L., et al. 2012, Sci, 336, 700

Russell, C. T., \& Raymond, C. A. 2011, in The Dawn Mission to Minor Planets 4 Vesta and 1 Ceres, ed. C. T. Russell et al. (1st ed.; New York: Springer), 3

Russell, C. T., Raymond, C. A., Ammannito, E., et al. 2016, Sci, 353 1008

Schmedemann, N., Kneissl, T., Neesemann, A., et al. 2016, GeoRL, 43, 11987

Schmidt, B. E., Hughson, K. H. G., Chilton, H. T., et al. 2017, NatGc, 10, 338

Schorghofer, N. 2016, Icar, 276, 88

Shepard, M. K., \& Helfenstein, P. 2007, JGR, 112, 1

Sierks, H., Keller, H. U., Jaumann, R., et al. 2011, in The Dawn Mission to Minor Planets 4 Vesta and 1 Ceres, ed. C. T. Russell et al. (1st ed.; New York: Springer), 263

Stephan, K., Jaumann, R., Krohn, K., et al. 2017, GeoRL, 44, 3

Titus, T. N. 2015, GeoRL, 42, 2130 